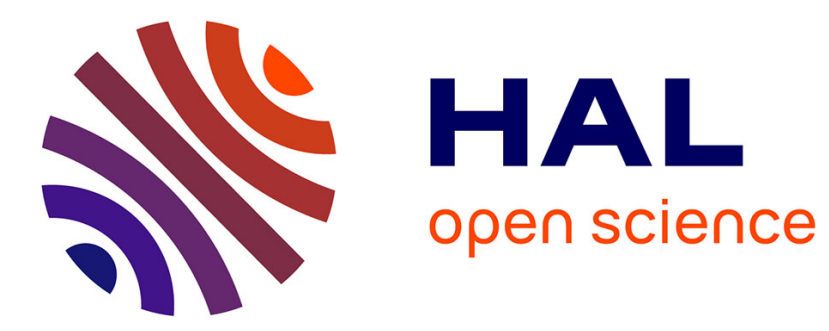

\title{
Temperature-Sensitive Amphiphilic Non-Ionic Triblock Copolymers for Enhanced In Vivo Skeletal Muscle Transfection
}

Bazoly Rasolonjatovo, Nicolas Illy, Véronique Bennevault, Jérôme Mathé, Patrick Midoux, Tony Le Gall, Thomas Haudebourg, Tristan Montier, Pierre Lehn, Bruno Pitard, et al.

\section{To cite this version:}

Bazoly Rasolonjatovo, Nicolas Illy, Véronique Bennevault, Jérôme Mathé, Patrick Midoux, et al.. Temperature-Sensitive Amphiphilic Non-Ionic Triblock Copolymers for Enhanced In Vivo Skeletal Muscle Transfection. Macromolecular Bioscience, 2020, 20 (3), pp.1900276. 10.1002/mabi.201900276 . hal-02451051

\section{HAL Id: hal-02451051 https://hal.sorbonne-universite.fr/hal-02451051}

Submitted on 23 Jan 2020

HAL is a multi-disciplinary open access archive for the deposit and dissemination of scientific research documents, whether they are published or not. The documents may come from teaching and research institutions in France or abroad, or from public or private research centers.
L'archive ouverte pluridisciplinaire HAL, est destinée au dépôt et à la diffusion de documents scientifiques de niveau recherche, publiés ou non, émanant des établissements d'enseignement et de recherche français ou étrangers, des laboratoires publics ou privés. 


\section{Temperature-Sensitive AmphiphilicNon-Ionic}

\section{TriblockCopolymers for Enhanced In VivoSkeletal}

\section{Muscle Transfection}

B.Rasolonjatovo, ${ }^{1,2}$ N.Illy, ${ }^{3}$ V.Bennevault,${ }^{3,4}$ J.Mathe,,${ }^{1,2}$ P.Midoux, ${ }^{5}$ T. Le Gall, ${ }^{6}$ T.Haudebourg, ${ }^{7}$

T.Montier, ${ }^{6}$ P.Lehn, ${ }^{6}$ B.Pitard, ${ }^{7}$ H.Cheradame, ${ }^{1,2}$ C.Huin,,${ }^{3,4}$ P.Guégan ${ }^{*}, 3$.

${ }^{1}$ LAMBE, CNRS, Université Evry, CEA, Université Paris-Saclay, 91025 Evry, France.

${ }^{2}$ LAMBE, UCP, Université Paris-Seine, 91025 Evry, France.

${ }^{3}$ Sorbonne Université, CNRS, Institut Parisien de Chimie Moléculaire,Equipe Chimie des Polymères, 4 place Jussieu, 75005 Paris, France

${ }^{4}$ Université of Evry, 91025 Evry, France

${ }^{5}$ Centre de Biophysique Moléculaire, CNRS UPR4301Orléans, 45071, Orléans cedex 02, France.

${ }^{6}$ Groupe «Transfert de gènes et thérapie génique », UMR 1078 "Génétique, Génomique Fonctionnelle et Biotechnologies", Université de Brest, INSERM, CHU de Brest, 22 avenue Camille Desmoulins, 29238 Brest cedex, France.

${ }^{7}$ CRCINA, INSERM, University of Angers, University of Nantes, Nantes, France. 
ABSTRACT. We report that low concentration of amphiphilictriblock copolymers of pMeOx- $b$ pTHF- $b$-pMeOx structure (TBCPs) improve gene expression in skeletal muscle upon intramuscular co-injection with plasmid DNA. Physicochemical studies carried out to understand the involved mechanism show that a phase transition of TBCPsunder their unimer state is induced when the temperature is elevated from $25^{\circ} \mathrm{C}$ to $37^{\circ} \mathrm{C}$, the body temperature. Several lines of evidences suggest that TBCP insertion in a lipid bilayer causes enough lipid bilayer destabilization and even pore formation, a phenomenon heightened during the phase transition of TBCPs. Interestingly, this property allows DNA translocation across the lipid bilayer model. Overall, the results indicate that TBCPs exhibiting a phase transition at the body temperature is promisingto favor in vivopDNA translocationin skeletal muscle cells for gene therapy applications.

\section{Introduction}

Gene therapy represents a great potential for curing a broad range of diseases, such as hereditary single-gene defects, cancers, viral infections, cardiovascular diseases, neurodegenerative disorders. ${ }^{[1-6]}$ Replacing a mutated gene responsible of cystic fibrosis, sickle cell anemia, hemophilia, Duchenne Muscular Dystrophy (DMD) has been reported and remains the only curing opportunity for these diseases. ${ }^{[7-10]}$ In the case of DMD, one of the goals is to deliver a gene encoding a functional version of the dystrophin in skeletal muscle (and, ultimately, cardiac muscle and diaphragm). ${ }^{[11,12]}$ The skeletal muscle transfection with naked 
plasmid DNA encoding the dystrophin gene is highly inefficient and does not result in significant dystrophin protein expression. ${ }^{[13]}$ One other strategy is to edit the mutated dystrophin gene by transfection of plasmid DNA encoding CRISPR-cas9. ${ }^{[14]}$ In both cases, the most critical step is the transfection efficiency of skeletal muscle cells, which requires the use of the appropriate vector or device to introduce the genetic material into the cells.

For this purpose, viral ${ }^{[15]}$ and chemical ${ }^{[16]}$ vectors have been developed. Current approaches make use of adeno-associated viruses $(\mathrm{AAV})^{[17,18]}$ to package the transgene, allowing efficienthost cells transfection. However, the main drawbacks are the immunogenicity, cytotoxicity, no specificity of transgene delivery, insertion mutagenesis and transgene size limitation of using viruses, even if progress in the improvement of viral vectors are performed. ${ }^{[15]}$

Chemical vectors attracted much attention and a rich library of polymers or lipids with various design strategies is proposed. ${ }^{[19-29]}$ Most of the investigated carriers present positive charges, ${ }^{[30-}$ ${ }^{34]}$ favoring the DNA condensation and its cellular uptake. Unfortunately, transfection efficiency in skeletal muscle is much lower with cationic vectors than naked DNA when intramuscularly injected. ${ }^{[35]}$

Amphiphilic non-ionic block copolymers provided then an interesting alternative to promote significant gene transfer to skeletal and cardiac muscles. ${ }^{[36]}$ The poly(ethylene oxide)- $b$ poly(propylene oxide)- $b$-poly(ethylene oxide) (PEO- $b$-PPO- $b$-PEO) family (Pluronics ${ }^{\circledR}$, Poloxamers ${ }^{\circledR}$, Lutrol $\left.{ }^{\circledR}\right)$ increased the transfection efficiency of plasmid DNA (pDNA), administered intramuscularly. ${ }^{[36-42]}$ Modifying molecular weight, EO/PO ratio and hydrophilic/lipophilic balance of the Pluronics ${ }^{\circledR}$ (L64, P85, P105) changed the levels of in vivo transgene expression. PEO was recently challenged in biological applications and its replacement 
by poly(2-methyl-2-oxazoline) derivatives was suggested. ${ }^{[43]}$ Poly(2-methyl-2-oxazoline)- $b$ poly(propylene oxide)- $b$-poly(2-methyl-2-oxazoline) (pMeOx- $b$-PPO- $b$-pMeOx) enhanced the luciferase activity by 20-times when co-administrated with pDNA compared to naked pDNA ${ }^{[44]}$ Replacing the PPO block of Pluronics ${ }^{\circledR}$ by a polytetrahydrofuran (pTHF) block reduced the toxicity. ${ }^{[45]}$ Cheradameet al. synthesized triblock copolymers pMeOx-b-pTHF- $b$ pMeOx with a short hydrophobic block and suggested their potential for pDNA transfection. ${ }^{[46,47]}$ In vitro experiments were conducted, and the poor transfection efficiencywere explained by the absence of interaction between DNA and the block copolymer. Other non-ionic amphiphilic block copolymers were developed: reverse Pluronics ${ }^{\circledR}$ PPO- $b$-PEO- $b$-PPO $25 \mathrm{R} 2$ was able to increase muscle transfection in a similar manner than $\mathrm{P} 105^{48}$ and a combination between poly(ethylene glycol)-b-poly(lactic glycolic acid)-b-poly(ethylene glycol) ( $\mathrm{PEO}_{13}-b$ $\left.\mathrm{PLGA}_{10}-b-\mathrm{PEO}_{13}\right)$ and plasmid DNA provides the potential to improve gene delivery efficiency in rat skeletal muscles. ${ }^{[49]}$

The mechanism(s) involved in the transfection efficiency of non-ionic amphiphilic copolymers is still unclear and deserves more investigations. Most of the Pluronics® do not interact with pDNA and do not protect them against DNase degradation. ${ }^{[50]}$ The polymer concentration has to be tuned to transfect the targeted striated muscles (skeletal vs. cardiac). ${ }^{[50]}$ The chemical composition and structure of the hydrophilic blocks can be modified without any alteration of the transfection efficiency in vivo. ${ }^{[44,49]}$ The effect of the amphiphilic copolymers organization (selfassembly, micelles vs.unimers), and their physicochemical features (critical micellar concentration and temperature) on the transfection efficiency have to be considered. ${ }^{[40,41]}$ The ability of the Pluronics ${ }^{\circledR}$ to activate in vivo signaling pathways involving NF- $\kappa \mathrm{B}$ was proposed as a possible explanation. ${ }^{[51,52]}$ The improvement of DNA diffusion in the muscle tissue by using 
Pluronics ${ }^{\circledR}$ was also proposed. ${ }^{[38,41]}$ Recent works stated that in vivo,Lutrol ${ }^{\circledR}$ directly delivered pDNA in the cell cytoplasm via a non-endocytosis process. ${ }^{[37]}$ Sahay et al. ascertained that the internalization pathway of Pluronic ${ }^{\circledR}$ P85 in mammalian cells happens through endocytosis: unimers are internalized through caveolae-mediated endocytosis, while micelles (and their payload) are internalized through clathrin-mediated endocytosis. ${ }^{[53]}$ Another assumption to explain the transfection efficiency is based on the ability of amphiphilic copolymers to span membrane lipid bilayers and to form transient pores. ${ }^{[54-62]}$

In this paper, different triblock copolymers (TBCP) of pMeOx- $b$-pTHF- $b$-pMeOx were synthesized comprising a hydrophobic block length fitting the thickness of a lipid membrane model $(\bar{X} n(\mathrm{pTHF})=10)$. Their properties were investigated in terms of in vivo transfection and temperature-dependent self-assembly. The interactions between copolymers and lipid membrane model were characterized by fluorescence and electrophysiological experiments. Moreover, the translocation of pDNA through a lipid bilayer model in presence of copolymers was studied. We discussed on a relationship between the copolymers behaviors in the absence and presence of a lipid membrane and their in vivo biological activities.

\section{Experimental Section}

\subsection{Reagents}

All reagents were purchased from Sigma (St. Quentin Fallavier, France) unless otherwise stated. Tetrahydrofuran (THF) was purified by distillation from sodium, under reflux, in the presence of benzophenone, until a persistent blue color appears. 2-Methyl-2-oxazoline (MeOx) was purified by refluxing over calcium hydride, under nitrogen, and distilled prior use. Acetonitrile $(\mathrm{ACN})$ and dichloromethane $\left(\mathrm{CH}_{2} \mathrm{Cl}_{2}\right)$ were dried by refluxing over $\mathrm{CaH}_{2}$ under 
$\mathrm{N}_{2}$ and subsequently distilled prior use. Deionized water was obtained with a Millipore Milli-Q system. Lutrol ${ }^{\circledR}$, provided by BASF, consists in a central PPO block of 30 propylene oxide units located between two poly(ethylene oxide) blocks of 75 monomer units. L- $\alpha$-phosphatidylcholine from egg yolk (EYPC) was purchased from Avanti Polar Lipids, Inc. and used as received. 5(6)Carboxyfluorescein and Triton $\odot$ X-100 (molecular biology grade) were purchased from SigmaAldrich.

\subsection{Synthesis of the triblock copolymers TPCBs}

The syntheses of the amphiphilictriblock ABA copolymers (pMeOx- $b$-pTHF- $b$-pMeOx) were performed by sequential cationic ring-opening polymerizations of tetrahydrofuran (THF) and 2-

methyl-2-oxazoline (MeOx) ${ }^{[61,63-65]}$ Typically, $5.8 \mathrm{mmol}$ of trifluoromethanesulfonic anhydride $\left(\mathrm{Tf}_{2} \mathrm{O}\right.$ ), solubilized in $10 \mathrm{~mL}$ of dry $\mathrm{CH}_{2} \mathrm{Cl}_{2}$, was added at $-9^{\circ} \mathrm{C}$ to $84 \mathrm{mmol}$ of dry THF. After 15 min, the polymerization was quenched by adding $19 \mathrm{mmol}$ of $\mathrm{MeOx}$ at $-9^{\circ} \mathrm{C}$. Residual THF was evaporated under reduced pressure. The resulting $\alpha, \omega$-dioxazolinium-pTHF polymer was dissolved in $40 \mathrm{~mL}$ of dry acetonitrile. Then, $88 \mathrm{mmol}$ of $\mathrm{MeOx}$ was added at $80^{\circ} \mathrm{C}$. After $3 \mathrm{~h}$, the reaction was quenchedby adding $4 \mathrm{~mL}$ of $1 \mathrm{M} \mathrm{Na}_{2} \mathrm{CO}_{3}$. The reaction medium was stirred for another $1 \mathrm{~h}$ at room temperature. The triblock copolymer was obtained by chloroform extraction, evaporation of the organic phase and drying for 2 days under vacuum. The molar mass of the two blocks was adjusted with the polymerization times.

\subsection{Characterization of the triblock copolymers TBCPs in solution}

The molar mass of the triblock copolymers was determined by ${ }^{1} \mathrm{H}$ NMR analysis at $300 \mathrm{MHz}$ in $\mathrm{CDCl}_{3}$ at room temperature on a BrukerAvance $\mathrm{AM} 300$ spectrometer. The molar mass and dispersity (Đ) were determined by size exclusion chromatography (SEC) at $25^{\circ} \mathrm{C}$ with $\mathrm{CHCl}_{3}$ as 
eluent $\left(1 \mathrm{~mL} \cdot \mathrm{min}^{-1}\right)$ and a copolymer concentration of $5 \mathrm{mg} \cdot \mathrm{mL}^{-1}$. The columns were a PSS GRAM $10^{3} \AA$ and a PSS GRAM $30 \AA \AA$. The SEC was calibrated using PS standards.

Dynamic light scattering (DLS) measurements were performed by using a Zetasizer Nano Series ZS (Malvern) equipped with a laser He-Ne $4 \mathrm{~mW}$ operating at $633 \mathrm{~nm}$. The data were acquired by using a BI-9000AT digital correlator fitted with the instrument. The autocorrelation functions were measured at a $173^{\circ}$ backscattering angle and analyzed by the constrained regularized CONTIN method to obtain distributions of decay rates $(\Gamma)$. The decay rates afford the determination of the distributions of apparent diffusion coefficients and the apparent hydrodynamic radii. ${ }^{[61]}$ TBCPs were directly dissolved in deionized water. The solutions were filtered through Millipore Millex filters ( $0.45 \mu \mathrm{m}$ pore size) and kept overnight. Critical Micellar Concentrations (CMC) were determined by plotting the hydrodynamic radius of the copolymers measured by DLS as a function of their concentration and have already been discussed. ${ }^{[61]}$ To determine the possible Critical Micellar Temperature (CMT), the hydrodynamic radii of the triblock copolymers were plotted as a function of temperature, from $10^{\circ} \mathrm{C}$ to $70^{\circ} \mathrm{C}$, at different concentrations of $0.1,1$ and $10 \mathrm{mg} \cdot \mathrm{mL}^{-1}$ in deionized water.

The CMC were also determined by fluorescence spectroscopy using Nile Red as fluorescent probe ${ }^{[61]}$ TBCP were dissolved directly in deionized waterat increasing concentrations. Then, Nile Red was added at a final concentration of $2.5 \mu \mathrm{mol} . \mathrm{L}^{-1}$, and the fluorescence intensity was measured at $630 \mathrm{~nm}$ upon excitation at $530 \mathrm{~nm}$ by usinga Shimadzu RF-5000 spectrofluorimeter. The maximum emission intensity at $630 \mathrm{~nm}$ was plotted as a function of TBCP concentrations. 


\subsection{Carboxyfluorescein leakage assay}

A $10 \mathrm{mg} \cdot \mathrm{mL}^{-1}$ carboxyfluorescein solution was prepared with Tris $\mathrm{C}$ buffer solution $(50 \mathrm{mM}$, $\mathrm{pH} 8.5$ ); the $\mathrm{pH}$ of the solution was adjusted to $\mathrm{pH} 7.4$ with a $0.5 \mathrm{~mol} . \mathrm{L}^{-1} \mathrm{HCl}$ solution. To make a vesicle sample, $1.0 \mathrm{~mL}$ of the carboxyfluorescein solution was added to $30 \mathrm{mg}$ EYPC in a vial. The lipid-carboxyfluorescein mixture was subjected to vortex mixing during 5 minutes. Then, unilamellar liposomes were prepared according to MacDonald et al. ${ }^{[66]}$ The solution was extruded through a WhatmanNucleopore polycarbonate membrane filter (19 mm diameter, $100 \mathrm{~nm}$ pore diameter) mounted in the LiposoFast Basic extruder apparatus (Avestin, Inc., Canada). The sample was subjected to 51-passages through the filter at room temperature. ${ }^{[67]}$ An odd number of passages was performed to avoid contamination of the sample by large and multilamellar vesicles, which might have not passed through the filter. Dynamic light scattering (DLS) confirmed the narrow size distribution and determined a $120 \mathrm{~nm}$ diameter size of the resulting vesicles. Freecarboxyfluorescein was removed by gel filtration on a Sephadex G-25 column. The final phospholipid concentration was adjusted to $0.75 \mathrm{mg} \cdot \mathrm{mL}^{-1}$ with Tris buffer, $\mathrm{pH} 7.4$, which has been determined as the best concentration for the subsequent kinetic release experiments. The vesicle solution was kept in a sealed glass vial in the dark at $4{ }^{\circ} \mathrm{C}$. No further treatment was applied prior to use.

Dye release from phospholipid vesicles was determined as follows: $100 \mu \mathrm{L}$ of $50 \mathrm{mMTris}$ buffer, $\mathrm{pH} 7.4$ containing TBCP was injected in $2.5 \mathrm{~mL}$ of the vesicle solution in a quartz cuvette to reach the final concentration of $0.77 \mathrm{mg} \cdot \mathrm{mL}^{-1}$. This value is not too far from the copolymer concentration giving the highest in vivo transfection and the release time is compatible with the experiment treatment. After homogenization, the fluorescence was measured by using aVarian Cary Eclipse fluorescence spectrophotometer with excitation at $490 \mathrm{~nm}$ and emission at 520 
$n m \cdot{ }^{[68]}$ The excitation and emission band widths were 3 and $5 \mathrm{~nm}$, respectively. The maximum fluorescence intensity was determined by adding $0.1 \mathrm{~mL}$ of a $1 \%$ Triton X-100 solution.

\subsection{Black Lipid Membrane Experiments}

Interactions of TBCPs with a lipid membrane modelmade of diphytanoylphosphatidylcholine (Avanti Polar Lipids, Inc.) were studied according to the 'Black Lipid Membrane' (BLM) technique. ${ }^{[57]}$ The electrolyte used was a $1 \mathrm{M} \mathrm{KCl}$ (the measured intensity is related to the salt concentration, and this salt concentration is required to get enough information in the data analysis step), 5mM HEPES, buffer $\mathrm{pH}$ 7.4. The BLM technique consists in measuring the current between two $\mathrm{Ag}-\mathrm{AgCl}$ electrodes, each being dipped into one of the two chambers of the measurement device connected by a $150 \mu \mathrm{m}$ diameter hole, on which is painted the lipid bilayer from a decane solution $(10 \mathrm{mg} / \mathrm{mL})$ (Warner Instruments, Hamden, CT). The capacitances of the membranes were above $50 \mathrm{pF}$, to ensure the formation of a membrane bilayer. Ionic current measurements were conducted to assess the formation of the bilayer and then to characterize the interactions of TBCPs with the membrane. Increasing concentrations of the copolymer was added to the is compartment only. All the presented BLM results were obtained at least for two different experiments.

For the data acquisition, the ionic current through the membrane was measured by using a BLM 120 amplifier (Biologic, Axon Instruments, Sunnyvale, CA, USA), the sampling frequency being $1500 \mathrm{~Hz}$ and the filter frequency $300 \mathrm{~Hz}$.

Ionic current measurements at $37^{\circ} \mathrm{C}$ were performed by using a dedicated set-up. The volume of the cell measurement was about $100 \mu \mathrm{L}$. The Teflon cell, embedded in a copper holder, was 
thermalized at a temperature varying from 5 to $70 \pm 0.1^{\circ} \mathrm{C}$ using a Peltier module connected to a temperature controller (Newport, Irvine, CA).

\subsection{Translocation of plasmid DNA through a model lipid bilayer}

After formation of the lipid bilayer, TBCP was added in the cis chamber at a concentration of $10 \mu \mathrm{g} \cdot \mathrm{mL}^{-1}$ and ionic current measurements were then recorded for a voltage of $-100 \mathrm{mV}$. Once the first interactions between TBCP and the lipid membrane were observed, the pGL3-ctrl (Promega Madison, WI, USA; 5256 base pairs) plasmid DNA (pDNA) was added in the trans chamber at a concentration of about $160 \mu \mathrm{g} \cdot \mathrm{mL}^{-1}$. The ionic current was then applied again with a voltage of $-100 \mathrm{mV}$. After $35 \mathrm{~min}$, the solutions in cis and trans chambers were carefully collected to avoid any disruption of the membrane. The quantity of pDNA in each chamber was finally determined by using the QuantiTect SYBR Green qPCR kit (Qiagen, Chatsworth, CA, USA) in accordance with the manufacturers' recommendations, as previously reported. ${ }^{[57]}$

\subsection{Intramuscular gene transfer}

Transfection efficiency was measured by analyzing the luciferase activity in the injected tibialis anterior muscles. Plasmid pGWIZ-Luc (Gelantis) encoding luciferase under the CMV promoter was amplified in E. coli and purified by using Qiagen Endo free kits (Qiagen).

Eight weeks old female Swiss mice were purchased from Janvier (Le Genest Saint Isle, France) and were housed in conventional conditions according to INSERM (Institut National de la Santé et de la RechercheMédicale) guidelines. All animal experiments were performed in accordance with the recommendations of French Ministry of Higher Education and Research, and approved by an ethics committee on animal experimentation under reference APAFIS\#7897 
and 4118. Mice were anesthetized and injected in each shaved tibialis anterior muscle with $50 \mu 1$ of DNA/amphiphilictriblock copolymer formulations prepared in Tyrode. Seven days after injection muscles were collected, homogenized in $1 \mathrm{~mL}$ of reporter lysis buffer (Promega), supplemented with protease cocktail inhibitor (Roche). Luciferase expression was measured in the supernatant, in duplicate and expressed as counts per second (CPS) in the whole muscle.

\subsection{Statistical analysis}

Statistical analyses were performed using GraphPad Prism Software (L Jolla, CA, USA). Values are expressed as the mean $+/$ SEM. Significant differences between groups are indicated $*<\mathrm{p} 0.05$, $* * \mathrm{p}<0.01, * * * \mathrm{p}<0.001$ by multiple $\mathrm{t}$ tests.

\section{Results}

\subsection{Synthesis and characterization of pMeOx-b-pTHF-b-pMeOx (TBCPs).}

Three amphiphilictriblock ABA copolymers, composed of poly(2-methyl-2-oxazoline) (pMeOx) as hydrophilic block A and polytetrahydrofuran (pTHF) as hydrophobic block B, were synthesized by sequential cationic ring-opening polymerization of tetrahydrofuran then 2methyl-2-oxazoline (Figure 1). ${ }^{[61]}$

The experimental conditions used for the synthesis are reported in Table S1. TBCPs were analyzed by SEC and ${ }^{1} \mathrm{H}$ NMR to confirm their polymeric structure and access to their molar mass (Figures S2-S3). The dispersity of the copolymers is higher than expected due to the

reversible polymerization of THF. As previously reported, ${ }^{1} \mathrm{H}$ NMR provided molar mass more 
reliable for this block copolymer family, and will be used for the discussion. ${ }^{[61]}$ The low $\bar{X}$ nof the pTHF block led to a contour length of the hydrophobic block close to the thickness of the hydrophobic part of lipid bilayers and cell membranes. The molar mass of the pMeOx blocks was varied to modify the Hydrophilic-Lipophilic Balance (HLB) of the block copolymers. TBCP8 has a high HLB with a relatively high molar mass. TBCP1 and TBCP3 have approximately the same HLB, with slightly different block molar masses.

The critical micellar concentrations (CMC) were determined by dynamic light scattering (DLS) and fluorescence spectroscopy of copolymers solubilized in deionized water. ${ }^{[61]}$ Table 1 gathers the molecular parameters of TBCPs and their main important physicochemical properties.

\subsection{In vivo transfection.}

The ability of TBCPs to improve pDNA transfection in the skeletal muscles of mice was evaluated and compared to naked DNA and Lutrol ${ }^{\circledR}$ at $30 \mathrm{mg} \cdot \mathrm{mL}^{-1}$, the optimized concentration for this copolymer. ${ }^{[36]}$ Ten $\mu$ g of pDNA encoding the luciferase gene were mixed with various concentrations of TBCPs. The mixtures were injected into shaved tibialis anterior muscles of Swiss mice. Seven days after injection, the muscles were harvested and the luciferase activity was measured (Figure 2). The Lutrol ${ }^{\circ}$ concentration was set at a value giving the best gene transfer results. ${ }^{[36]}$ During this short period of time, there was no modification of the body weight of the injected mice.

TBCP3 of intermediate HLB and number of THF units in the hydrophobic block was selected for concentration dependence study. At $10 \mathrm{mg} \cdot \mathrm{mL}^{-1}$, the luciferase activity was comparable to the one of naked DNA. Luciferase activity in harvested muscles transfected with $1 \mathrm{mg} \cdot \mathrm{mL}^{-1}$ of 
TBCP 3 was of the same order than the one measured with Lutrol ${ }^{\circledR}$ at its optimal concentration of $30 \mathrm{mg} \cdot \mathrm{mL}^{-1}$. At $0.1 \mathrm{mg} \cdot \mathrm{mL}^{-1}$, the luciferase activity was 10 -fold and 2.5 -fold higher than the one of naked DNA and Lutrol ${ }^{\circledR}$, respectively. Transfection efficiency increased when TBCP3 concentration decreased. However, no effect on transfection was observed for $0.01 \mathrm{mg} \cdot \mathrm{mL}^{-1}$.

The three TBCPs were then used at $1 \mathrm{mg} \cdot \mathrm{mL}^{-1}$ to study the effect of the $\mathrm{N}_{\mathrm{THF}} / \mathrm{N}_{\mathrm{MeOx}}$ ratio on pDNA transfection, for a given molar mass of pTHF. TBCP8 lead to luciferase activity 4-fold higher than naked pDNA, and was comparable to the one of Lutrol ${ }^{\circledR}$ at $30 \mathrm{mg} \cdot \mathrm{mL}^{-1}$. The luciferase activity of pDNA with $1 \mathrm{mg} \cdot \mathrm{mL}^{-1}$ of TBCP3 was of the same order than the one measured with ТВCP8. However, the luciferase activity with ТВCP1 was 8 -fold higher than the one of naked DNA and 2-fold higher than the one of Lutrol ${ }^{\circledR} 30 \mathrm{mg} \cdot \mathrm{mL}^{-1}$. Lower TBCP1 concentration did not improve the transfection efficiency.

Overall, co-administration of pDNA with TBCPs, especially TBCP3 provided enhanced gene expression in skeletal muscle as obtained with pDNAand Lutrol ${ }^{\circledR}$ but at lower concentration for TBCP(1 mg.mL $\left.{ }^{-1} v s .30 \mathrm{mg} \cdot \mathrm{mL}^{-1}\right)$.

\subsection{Self-aggregation of TBCP as a function of temperature.}

During the intramuscular injection, the $\mathrm{TBCP}$ undergoes a temperature elevation, from $20^{\circ} \mathrm{C}$ to $37^{\circ} \mathrm{C}$ that could modify itsphysicochemical properties. The aggregation of TBCP3 was first studied by DLS measurements. Figure 3 reports the hydrodynamic radius of TBCP3 at three different concentrations in deionized water as a function of temperature.

At $0.1 \mathrm{mg} \cdot \mathrm{mL}^{-1}$, the hydrodynamic radius of TBCP3 was close to $2.5 \mathrm{~nm}$ at room temperature, witnessing the presence of unimers only. The temperature elevation triggered a significant 
enhancement of the hydrodynamic radius due to the aggregation of TBCP3 into micelles. Since $\mathrm{pMeOx}$ is soluble in water whatever the temperature, we suggest a dehydration of the pTHF block to form the corona of the micelle. ${ }^{[50]}$ The transition temperature occurred in the $25-50^{\circ} \mathrm{C}$ range, which was too large to suggest a clear critical micellar temperature (CMT). At $1 \mathrm{mg} \cdot \mathrm{mL}^{-1}$, the effect was similar, i.e. the enhancement of the hydrodynamic radius of TBCP 3 as a function of temperature. The observed sharp transition suggested a CMT of $25^{\circ} \mathrm{C}$ at $1 \mathrm{mg} \cdot \mathrm{mL}^{-1}$. At 10 mg.mL $\mathrm{mL}^{-1}$, no variation of the hydrodynamic radius was observed, and the $6 \mathrm{~nm}$ value suggested the presence of aggregates as the main population, even at room temperature. In the case of TBCP8, no CMT was detected in the range of studied temperatures, at the concentration used for the gene transfer experiments, i.e. $1 \mathrm{mg} \cdot \mathrm{mL}^{-1}$. For TBCP1, a sharp increase of the hydrodynamic radius was observed as a function of the temperature, leading to a CMT of $42^{\circ} \mathrm{C}$ at $10 \mathrm{mg} \cdot \mathrm{mL}^{-1}$ (Figure S4). A slight CMT decrease could occur under physiological salt conditions (150 $\mathrm{mMNaCl}$ ) as reported for PEO- $b$-PPO- $b$-PEOL64, ${ }^{[69]}$ that has a CMT close to $60^{\circ} \mathrm{C}$ at a $1 \%$ concentration, a temperature range much higher than the body temperature (as reported for most pluronic polymers). ${ }^{[70]}$

\subsection{Effect of TBCP on membrane bilayers.}

Phospholipid liposomes are useful biomembrane models. ${ }^{[72]}$ Unilamellar EYPC liposomes of $\sim 100 \mathrm{~nm}$ were prepared by extrusion through pores in a polycarbonate filter $(50 \mathrm{~nm})$ in the presence of carboxyfluorescein in Tris buffer. According to Balgavyet al., ${ }^{[71]}$ EYPC liposomes have a bilayer thickness of $4.2 \mathrm{~nm}$. Carboxyfluorescein (CF) is an anionic dye at $\mathrm{pH} 7.4$ that was widely used to monitor pore formation and membrane stability. ${ }^{[72-74]}$ Gokelet coll. ${ }^{[75]}$ have determined that $\mathrm{CF}$ is no more than $\approx 10 \AA$ in any dimension according to $\mathrm{CPK}$ and computer 
models. External carboxyfluorescein was removed by size exclusion chromatography. The concentration of the dye inside the vesicles was high enough to promote self-quenching of the fluorescence. An aqueous solution of the amphiphilic copolymers was added to the liposome suspension to reach a final concentration of $0.77 \mathrm{mg} \cdot \mathrm{mL}^{-1}$, a value close to the lowest copolymer concentration used in the gene transfer assay, and providing signals compatible with the timescale of the experiment. The carboxyfluorescein release was monitored as a function of time by fluorescence measurements. When the dye is released from the vesicles and diluted into a much larger extra-vesicular volume, the fluorescence intensity increases and is proportional to the dye concentration (Figure 4).

After completion of the monitoring, the liposomes were lysed by addition of Triton X100 to measure the total fluorescence intensity in order to calculate the percentage of CF release. The CF release curves increased rapidly according to an exponential equation to reach a pseudoplateau (Figure 4). A time constant was determined for the percent of CF release with a previously described equation using an ordinary least squares method: $:^{[75-77]}$

$$
F_{\lambda=520}=F_{\lambda=520}^{t=0}+A \times\left(1-e^{-t / \tau}\right)+B \times t
$$

With $F_{\lambda=520}$ measured fluorescence at $520 \mathrm{~nm} ; F_{\lambda=520}^{t=0}$ fluorescence at the time of polymer injection; A the size of the exponential component; B the slope of the linear portion of the curve and $\tau$ the time constant for the pore activation. We have also chosen an arbitrary time point at 50 min to compare the copolymer CF releases (Table 2).

$\mathrm{CF}$ release allowed detecting pore formation or membrane leakage. According to Gokelet coll. ${ }^{[75]}$ the exponential portion of the curve corresponded to the vesicles that empty from a single pore activation. This pore formation was therefore the rate-limiting step, which could be 
described by the time constant $\tau$. According to Table 2, the order of transport efficiency is TBCP1 > TBCP3 > TBCP8 at $0.77 \mathrm{mg} \cdot \mathrm{mL}^{-1}$. After $50 \mathrm{~min}$, TBCP1 promoted the highest $\mathrm{CF}$ release, as well as the highest transfection efficiency. At this concentration, the CF release efficiency induced by the copolymer was in line with the gene transfer results.

The temperature effect on membrane permeation was therefore investigated. To mimic the in vivo gene transfection experiments, the TBCP solutions were prepared at $20^{\circ} \mathrm{C}$ and added to the vesicles at the investigated temperatures. The copolymer undergoes anincreased temperature directly in the presence of the lipid membranes, as it happens after intramuscular injectionof copolymer-pDNA formulations. At $0.77 \mathrm{mg} \cdot \mathrm{mL}^{-1}$, TBCP3 exhibiting a sharp CMT was then selected for the study (Figure 5).

The temperature varied from $20^{\circ} \mathrm{C}$ to $40^{\circ} \mathrm{C}$. At the highest temperature, the liposomes remained intact in the time scale of the experiments. The polymer addition in the vesicle solution resulted in a significant increase of the release rates (Table 3 ). The release was low at $20^{\circ} \mathrm{C}$. Sshaped release curves were observed when TBCP3 was added at temperatures higher than the CMT. The increasing temperature decreases the solvent-polymer interactions, favoring the liposome-TBCP3 interactionsinstead of the formation of TBCP3-aggregates in the presence of vesicles (suggested by the variation of CF release as a functionof temperature).

\subsection{Ionic current measurements in the presence of TBCPs.}

The formation of pores was investigated by 'Black Lipid Membrane' (BLM) measurements. ${ }^{57}$ This technique allows the observation of single events occurring in lipid bilayers. A current is measured through a lipid membrane model when a voltage is applied. The lipid membrane is separating two compartments filled with $1 \mathrm{M} \mathrm{KCl}$ solutions and is acting as an insulator. 
Perturbation of the membrane leads to the appearance of a current witnessing interactions or pore formation. The current measured during the BLM experiments gives information on the size of the pore, by comparison with the current value measured in the presence of $\alpha$-hemolysin, a biological nanopore used as reference. ${ }^{[78]}$ The internal diameter of $\alpha$-hemolysin is about $2 \mathrm{~nm}$ at $1 \mathrm{M} \mathrm{KCl}$, resulting in a current of $-100 \mathrm{pA}$ for an applied voltage of $-100 \mathrm{mV}$.

TBCPs alone were first studied with the diphytanoylphosphatidylcholinemodelmembrane, a standard phospholipidfound in the skeletal muscle membrane ${ }^{[57]}$ (Figure 6). Auvrayet coll. ${ }^{[5]}$, reported that Lutrolforms nanopores in such membrane through a carpet mechanism, involving few PEO- $b$-PPO- $b$-PEOmolecules. One recalls that the $\bar{X} n$ of the hydrophobic pTHF block (Table S1) was designed to fit with the thickness of the lipid membrane model (4-6 nm). In order to avoid membrane disruption and to be in a single-molecule scale necessary for this technique, the final concentration of copolymers was set in the range $10-100 \mu \mathrm{g} \cdot \mathrm{mL}^{-1}$. A much lower concentration was set compared to the one used for in vivo transfection in order to isolate the measured events and to avoid any fast lipid membrane disruption.

Figure 6-A represents a typical ionic current trace, current plotted as a function of time, obtained in presence of TBCP3 $\left(10 \mu \mathrm{g} \cdot \mathrm{mL}^{-1}\right)$ at $-100 \mathrm{mV}$. TBCP3 allowed an ion flux through the lipid membrane giving a maximal current of $\sim-20 \mathrm{pA}$ corresponding to an average pore diameter of $0.4 \mathrm{~nm}$ based on the values obtained for $\alpha$-hemolysin. ${ }^{[78]}$

Figure 6-B gives the usual data analysis of the ionic current trace, allowing plotting a histogram of current distribution, i.e. occurrence (number of events obtained at this current) as a function of current. On the histogram profile, the population present at $0 \mathrm{pA}$ corresponds to the lipid membrane (insulator). Then, a population of different events, at almost all the currents, was 
observed indicating that the structures of permeation are not well-defined, as already mentioned by using amphiphilic copolymers in presence of lipid membrane. ${ }^{[55,57,58]}$

The BLM data measured in presence of TBCP8 and TBCP1 were similar at the same concentration. The three TBCPs thus induce lipid membrane perturbation. By using different copolymer concentrations, it was possible to determine the number of macromolecules involved in the pore formation, thanks to Hill equation. ${ }^{[79]}$

$$
\log \mathrm{Y}=\mathrm{n} \log \mathrm{C}_{\mathrm{M}}-\mathrm{n} \log \mathrm{K}_{\mathrm{D}}
$$

with $\mathrm{Y}$ : fractional activity (or $\left.\mathrm{P}_{0}\right)$

$\mathrm{C}_{\mathrm{M}}$ : macromolecule concentration,

n: Hill coefficient,

$\mathrm{K}_{\mathrm{D}}$ : dissociation constant of the supramacromolecules.

$\mathrm{P}_{0}$ is the pore opening probability, defined as the ratio between time of interactions and time of acquisition. The Hill coefficient $\mathrm{n}$ obtained from the curve $\log \left(\mathrm{P}_{0}\right)$ versus concentration corresponds to the number of macromolecules involved in the pore formation. $\mathrm{n}$ equal to 1 corresponds to a monomolecular channel and $\mathrm{n}>1$ corresponds to a multimolecular channel.

The Hill equation is commonly used for biological pores that have a definite structure. Modifying the concentration and determining the opening probability versus the concentration of TBCPs was performed (Figure S5). Only one macromolecule of each TBCP seemed to be necessary to let ions passing through the lipid membrane, which was consistent with the unimer phase of the copolymers at this concentration. 


\subsection{TBCP-assisted pDNA translocation through lipid bilayers.}

The 'BLM' results demonstrated a TBCP-assisted lipid membrane permeation allowing the translocation of ions through pore of diameter around $0.4 \mathrm{~nm}$. The question whether macromolecules, especially DNA, could also pass through pores thanks to TBCPs is of main interest for transfection application. Another question concerned the effect of the temperature on the TBCP3-mediated translocation.

BLM experiments in the presence of a well-defined DNA i.e. plasmid DNA of $9680 \mathrm{kbp}$ and TBCPs were performed. First, we demonstrated that no pDNA translocation through this lipid bilayer was observed in our experimentalconditions. Next, TBCP was first added at a final concentration of $10 \mu \mathrm{g} \cdot \mathrm{mL}^{-1}$ in the cis chamber to allow its interaction with the membrane under $-100 \mathrm{mV}$. Then, pDNA at the final concentration of $\sim 160 \mu \mathrm{g} \cdot \mathrm{mL}^{-1}$ was added in the trans chamber and a voltage of $-100 \mathrm{mV}$ was appliedagain. This allowed continuing to study the interactions of the polymer with the membrane, while promoting DNA translocation from one chamber to the other according to the direction of the applied voltage. The current, representing the interactions between the polymer and the lipid membrane, was recorded during 35 min, in a way to observe the pore formation. Then, the solutions in the cis and trans chambers were carefully collected to avoid the membrane disruption, and the amount of pDNA in both chambers was quantified by qPCR. It is noteworthy that the concentration of pDNA in trans was intentionally high to have a better chance to observe its translocation.

Table 4 summarizes the BLM experiments and the quantification of pDNA in each chamber after 35 min. Concerning the BLM data, Figure S6-A represents the current versus time during 
the translocation experiments and Figure S6-B represents the analysis of the observed events, for TBCP8, at room temperature. Interactions with important current jumps (-100 pA for an applied voltage of $-100 \mathrm{mV}$ ) occurred (Figure S6-A). The all-points histogram (occurrence versus current) allowed demonstrating that a large range of current values is measured at the beginning of the acquisition (Figure S6-B, logarithmic scale), meaning that interactions were not welldefined. However, a long-lasting porewith a current jump of approximately $-2 \mathrm{pA}$ for an applied voltage of $-100 \mathrm{mV}$ was obtained at the end of the acquisition (1500s) (visible on Figures S6-B and S6-C).

In the presence $\mathrm{TBCP} 1$ at $25^{\circ} \mathrm{C}$, interactions with important current $(-100 \mathrm{pA}$ at $-100 \mathrm{mV})$ were also observed (Figure S7-A). However, well-defined discrete current jumps were observedfor TBCP1 on the histogram of events varying from -2 pA (Figure S7-C, linear scale) to -20 pA (Figure S7-B, logarithmic scale). Black arrows on the figures highlight their multiples (Figure S7-B). Such discrete current signals were not observed for TBCP8.

For TBCP3, interactions with important current jumps $(-100 \mathrm{pA}$ at $-100 \mathrm{mV})$ occurred at $25^{\circ} \mathrm{C}$ (Figure S8-A) with also large current distribution (Figure S8-B). Same type of events were observed at $37^{\circ} \mathrm{C}$, except that the current jumps were much higher $(-400 \mathrm{pA}$ at $-100 \mathrm{mV})$ (Figure S9-A). Experiments with TBCP1 at $1 \mathrm{mg} \cdot \mathrm{mL}^{-1}$ were not performed because its mild critical temperature transition occurring at $42^{\circ} \mathrm{C}$ caused thermal instability of the lipid bilayer leading to disruption.

qPCR analysis demonstrated that translocation of pDNA occurred in presence of TBCPs; the highest translocation efficiency being reached with $\mathrm{TBCP} 3$ at $37^{\circ} \mathrm{C}$. It is important to note that in each case, pDNA was not detected in the cis chamber when no copolymer was added in the trans 
chamber thus validating the role of TBCPs in pDNA translocation through the lipid membrane model.

\section{Discussion}

Three TBCPs were synthesized and their capacity to increase the transfection efficiency of pDNA encoding the luciferase gene in mice skeletal muscles was tested upon intramuscular injection in the tibialis anterior muscles of Swiss mice. These triblock copolymers were found to enhance the transfection efficiency as determined through luciferase activity compared to naked pDNA, whatever their molar mass or theirHLB.This category of in vivo synthetic delivery vectors consisting of amphiphilic block copolymers of triblock copolymers including different compositions of the hydrophilic and hydrophobic blocks, has been widely used for efficient and safe in vivo delivery of DNA. Indeed, formulations composed of pDNA and triblock copolymer have been described to transfect skeletal and cardiac muscles ${ }^{80-83}$. Ability of those block copolymers to deliver DNA in muscles for expression of gene of therapeutic interest has been demonstrated in mouse model of hepatocellular carcinoma ${ }^{84}$, of allergic asthma ${ }^{85}$ or of colorectal cancer $^{86}$. Importantly, results of all of those studies show that amphiphilic block copolymer/DNA formulations were well tolerated and did not induce mortality nor toxicity when compared to control animals injected with saline solution.

The copolymers with lower molar mass (TBCP3 at $0.1 \mathrm{mg} \cdot \mathrm{mL}^{-1}$ and TBCP1 at $1 \mathrm{mg} \cdot \mathrm{mL}^{-1}$ )

offered better transfection efficiencies than Lutrol ${ }^{\circledR}$ at $30 \mathrm{mg} \cdot \mathrm{mL}^{-1}$ selected as the copolymer reference. TBCP8 at $1 \mathrm{mg} \cdot \mathrm{mL}^{-1}$ gave a transfection efficacy comparable to Lutrol ${ }^{\circledR}$. 
The good transfection efficiency is correlated to the presence of TBCP unimers at room temperatureat the concentration providing the best transfections. These results are in line with those reported for Pluronic ${ }^{\circledR}$ L64 $\left[{ }^{[40]}\right.$ The authors showed that the conditions favoring interactions between unimers (medium, temperature) displayed maximal efficiency in vivo after intramuscular injection in normal and dystrophic muscles. ${ }^{[40]} \mathrm{At} 37^{\circ} \mathrm{C}$, the temperature of the animal body, we demonstrate that TBCP 8 and TBCP3 were in a micellar stateat $1 \mathrm{mg} \cdot \mathrm{mL}^{-1}$, whereas TBCP1 was in an unimer state. However, TBCP3 undergoes a mild transition from unimer to micelles at $0.1 \mathrm{mg} \cdot \mathrm{mL}^{-1}$ in the range of 27 to $45{ }^{\circ} \mathrm{C}$. Thus, the good transfection efficiency is likely ascribed to the TBCP3 concentration at which a CMT close to $37{ }^{\circ} \mathrm{C}$ is observed. In this assumption, TBCP3 undergoes a phase transition during intramuscular injection, and the water depletion from the hydrophobic pTHFblock may force the copolymer to interact with the cell membrane.

TBCPs interact with lipid membrane (Figure 6). Indeed, they provided CF release from liposomes with efficacy at $0.77 \mathrm{mg} \cdot \mathrm{mL}^{-1}$ and at room temperature in the following order TBCP1 $>$ TBCP3 > TBCP8; TBCP1 providing the highest release after 50 minutes. This result was in line with the observed gene transfer efficiency. BLM revealed that the active concentration of the copolymers was in the range of $10-100 \mu \mathrm{g} \cdot \mathrm{mL}^{-1}$, lower than the one used for fluorescence experiments and in vivo assays. TBCPs destabilize the lipid membrane but the permeation mechanism is not well-defined, as already mentioned for other amphiphilic copolymers. ${ }^{[55,57,58]}$ The Hill plot indicated that only one macromolecule can induce the pore formation, which is in line with their unimer phase at this concentration. This copolymer insertion in the lipid membrane is favored by the good fit between the hydrophobic contour length of the pTHF block and the hydrophobic thickness of the lipid bilayer. Small Angle X-Ray 
Scattering showed that when the hydrophobic PPO block length of Pluronics ${ }^{\circledR}$ is lower than the thickness of dimyristoyl-sn-glycero-3-phosphocholine or DMPC bilayer, few amounts of copolymer are integrated in the bilayer and the PEO blocks are oriented laterally to the membrane surface, which may seal defects on the surface of the membrane. ${ }^{[87]}$ When the PPO block and the bilayer thickness have the same size, the copolymer is well anchored in the membrane and the hydrophilic PEO blocks is perpendicular to the surface of the membrane. Two processes are discussed for the pore formation of Pluronic ${ }^{\circledR}$ L64. ${ }^{[55]}$ The barrel stave mechanism was comparable to biological channel permeation structures, where pores form a defined structure like $\alpha$-hemolysin for instance. ${ }^{[78]}$ This mechanism could occur with block copolymers when the hydrophobic length block is fully extended in the lipid bilayers, and then stabilizes the inner surface of the resulting pore. The carpet mechanism corresponds to a partial insertion of the block copolymer in the lipid membrane. The adsorbed polymer induces a local change of the lipid membrane curvature forming a transient hole in the bilayer.

qPCR analyses validate the pore-assisted pDNA penetration through the membrane via TBCP insertion in the membrane. At the concentration used in the BLM experiments and at $25^{\circ} \mathrm{C}$, the three TBCPs are in the unimer phase and the translocation (although significant) is really weak. Higher translocation efficiency is observed with $\mathrm{TBCP} 3$ at $37^{\circ} \mathrm{C}$, the polymer that actually allows the best transfection efficiency in our experiments carried out in mice. It is thus noteworthy that the highest $\mathrm{I}_{\text {mean }}$ measured for $\mathrm{TBCP} 3$ at $37^{\circ} \mathrm{C}$ corresponds to a higher pore diameter and correlates with the highest translocation efficiency (Table 4). BLM, under experimental settings close to physiological conditions can be an interesting technique to understand phenomena occurring in vivo. Before injection, in the mixture containing pDNA, TBCP 3 exhibits a unimer phase at $25^{\circ} \mathrm{C}$. After intramuscular injection, it is organized in micelles 
at $37^{\circ} \mathrm{C}$ and/or better interacts with cell membranes. The temperature-dependent self-assembly of TBCPs thus is likely an essential parameter for DNA translocation through cell membrane providing high transfection efficiency.

\section{Conclusions}

The present work relies on the design of new competitive amphiphilictriblock copolymers of pMeOx- $b$-pTHF- $b$-pMeOxstructure that improve gene delivery in skeletal muscles. Several lines of evidences indicate that the temperature elevation during intramuscular injection is crucial for their positive impact on the transfection efficiency. The best TBCP undergoes a phase transition at temperature between $25-40^{\circ} \mathrm{C}$ and physicochemical studies support the insertion of TBCP in lipid bilayer allowing DNA translocation. A CMT between $25-40^{\circ} \mathrm{C}$ appears to be one of the driving forces that helps single molecule of copolymer to interact with the membrane of muscle cells after intramuscular injection and induces enough membrane destabilization to improve pDNAtranslocation in the cells. Altogether, our results highlight the interest of pMeOx- $b$-pTHF$b$-pMeOxblock copolymers exhibiting a phase transition around the body temperature to improve gene delivery in skeletal muscle cells for gene therapy and vaccine applications.

FIGURES.

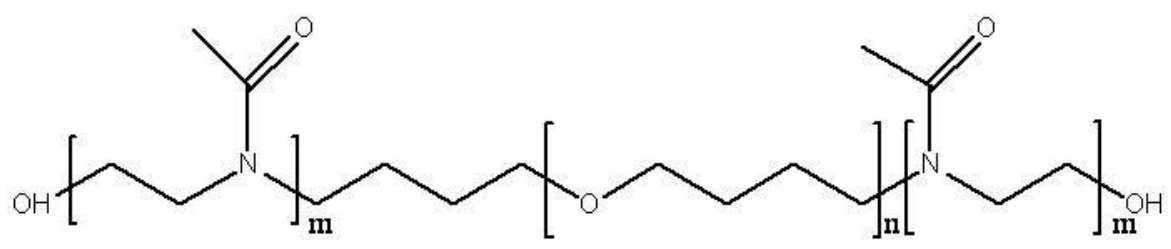


Figure 1.Chemical structures of amphiphilictriblock copolymers pMeOx- $b$-pTHF- $b$-pMeOx (TBCP).
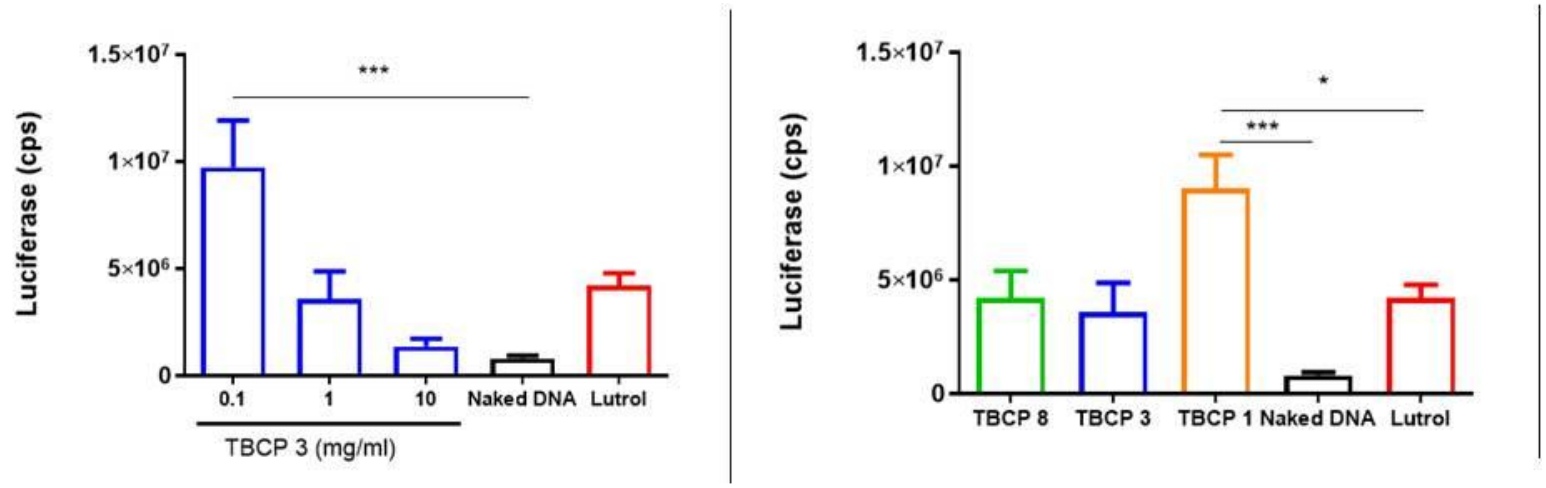

Figure 2.In vivo luciferase expression (cps/ muscle) in the mouse tibialis anterior muscle. (A) Luciferase activity was measured after intramuscular injection of $10 \mu \mathrm{g}$ of DNA associated with $0.1 \mathrm{mg} \cdot \mathrm{mL}^{-1}, 1 \mathrm{mg} \cdot \mathrm{mL}^{-1}$ and $10 \mathrm{mg} \cdot \mathrm{mL}^{-1}$ of the triblock copolymer TBCP3 and (B) $1 \mathrm{mg} \cdot \mathrm{mL}^{-1}$ of TBCP8, TBCP 3 and TBCP1. As controls, $30 \mathrm{mg} \cdot \mathrm{mL}^{-1}$ of Lutrol® and naked DNA were used. Luciferase expression was monitored 7 days post-injection. Data were analyzed using multiple $\mathrm{t}$ tests $* * * \mathrm{p}<0.001, * \mathrm{p}<0.05$

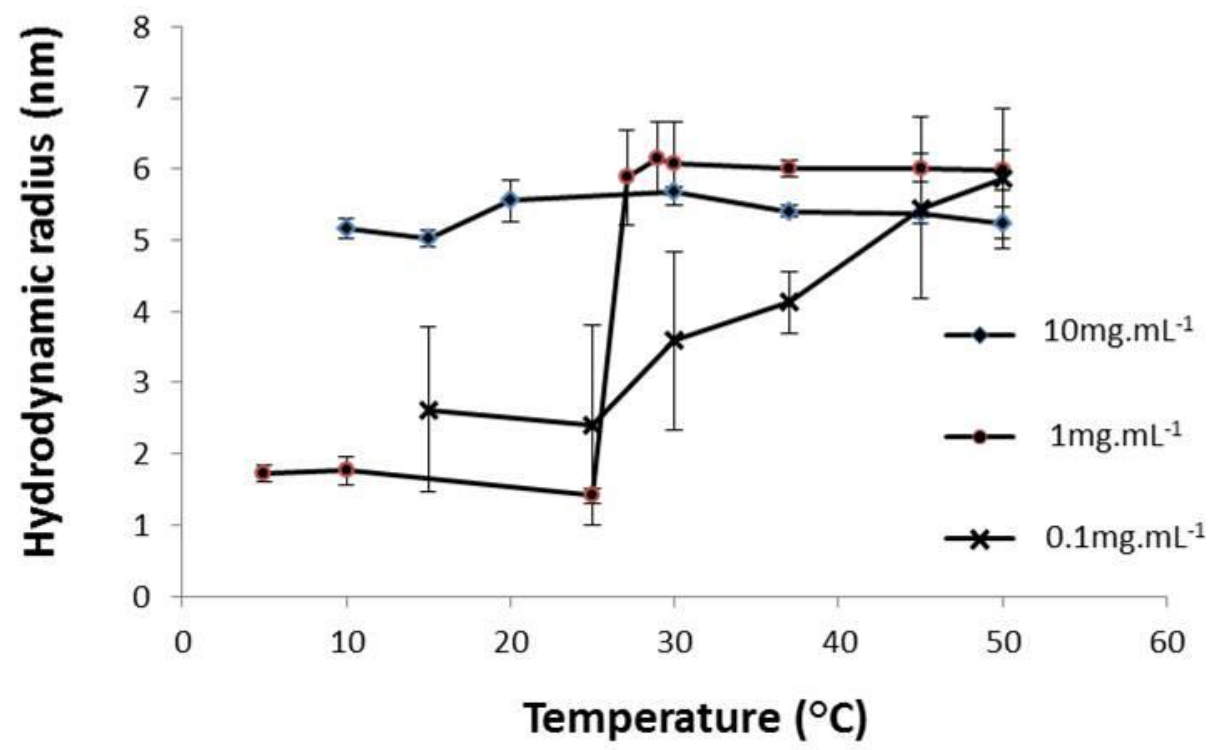


Figure 3. Hydrodynamic radius of TBCP3 in deionized water as a function of temperature and concentration.

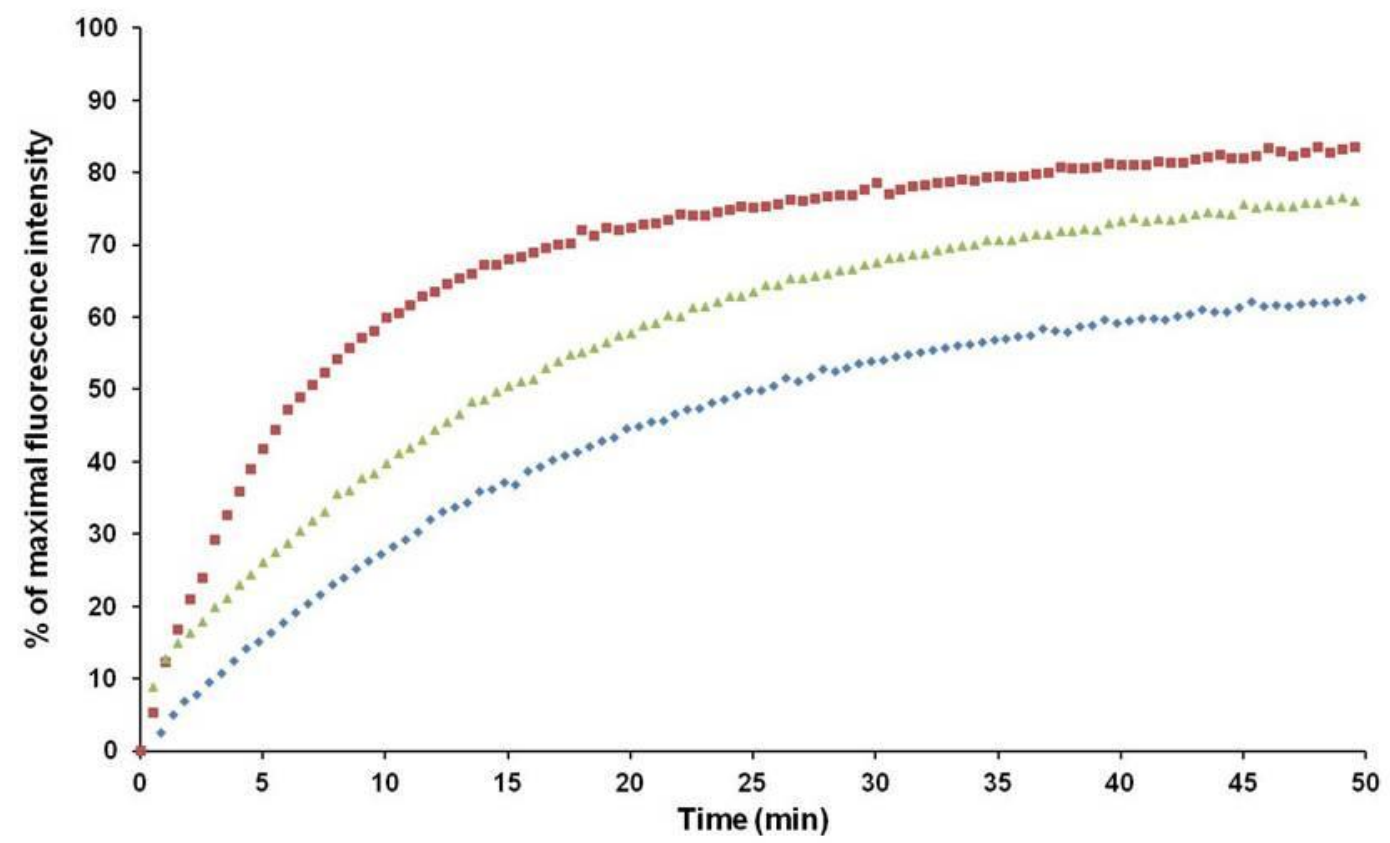

Figure 4.Carboxyfluorescein release from lipid vesicles at $20^{\circ} \mathrm{C}$ in the presence of $\mathrm{TBCP} 8$ (blue), TBCP1 (red) or TBCP3 (green). The copolymers were added to the vesicles solution, at a final concentration of $0.77 \mathrm{mg} \cdot \mathrm{mL}^{-1}$, followed by a stirring of 2 seconds before fluorescence measurements. 


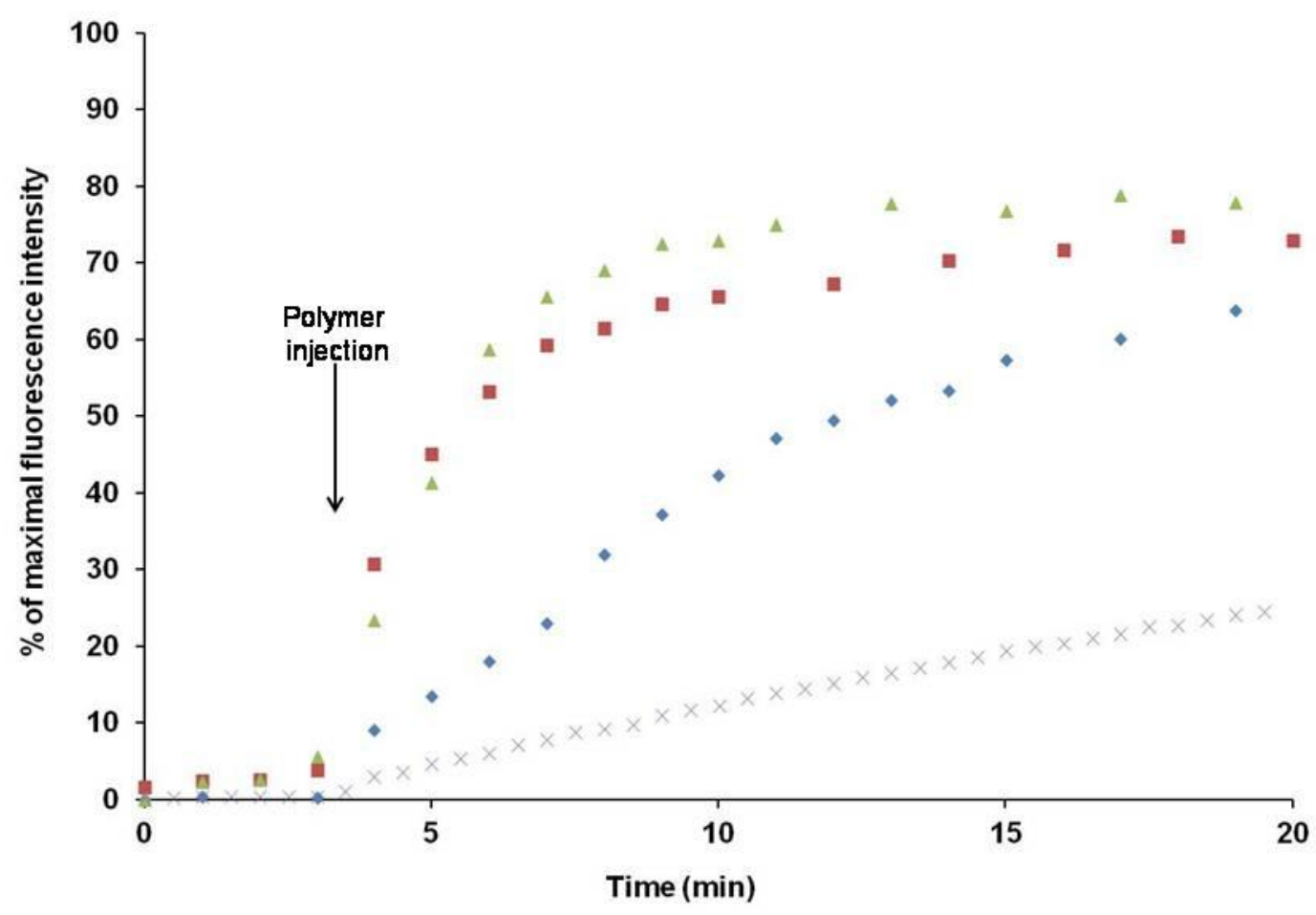

Figure 5.Carboxyfluorescein release from lipid vesicles in the presence of TBCP3 at (grey) $20^{\circ} \mathrm{C}$, (blue) $30^{\circ} \mathrm{C}$, (red) $35^{\circ} \mathrm{C}$ and (green) $40^{\circ} \mathrm{C}$. The copolymers were added at $0.77 \mathrm{mg} \cdot \mathrm{mL}^{-1}$ to the vesicles solution without any stirring. 

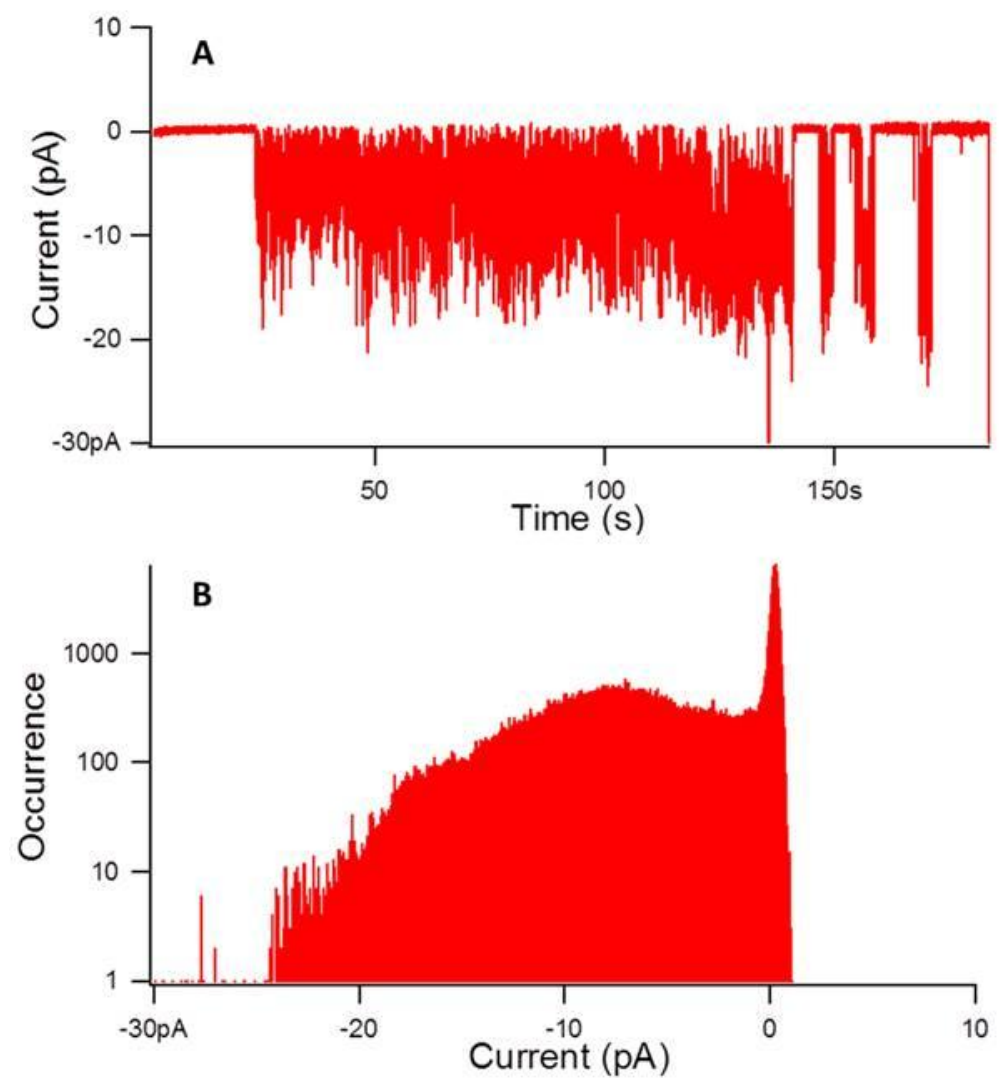

Figure 6. BLM results for TBCP3 at $10 \mu \mathrm{g} \cdot \mathrm{mL}^{-1}$, for an applied voltage of $-100 \mathrm{mV}$, in $1 \mathrm{M}$ $\mathrm{KCl}$, $5 \mathrm{mM}$ HEPES, $\mathrm{pH}=7.4$, at room temperature (A) Current as a function of time. (B) Occurrence as a function of current (current distribution). 
TABLES.

Table 1. Characteristics of pMeOx- $b$-pTHF- $b$-pMeOxamphiphilictriblockcopolymersTBCPs. ${ }^{[61]}$

\begin{tabular}{ccccccccc}
\hline TBCP & HLB & $\mathrm{N}_{\mathrm{THF}}$ & $\mathrm{N}_{\mathrm{MeOx}}$ & $\begin{array}{c}\overline{\boldsymbol{M n}} \\
\left({ }^{1} \mathrm{H} \mathrm{NMR}\right) \\
{\left[\mathrm{g} \cdot \mathrm{mol}^{-1}\right]}\end{array}$ & $\begin{array}{c}\mathrm{CMC}^{\mathrm{a}, 60} \\
{\left[\mathrm{~mol}^{-1} \mathrm{~L}^{-1}\right]}\end{array}$ & $\begin{array}{c}\mathrm{CMC}^{\mathrm{a}, 60} \\
{\left[\mathrm{mg}_{\mathrm{mLL}}{ }^{-1}\right]}\end{array}$ & $\begin{array}{c}\mathrm{CMC}^{\mathrm{b}, 60} \\
{\left[\mathrm{~mol} \cdot \mathrm{L}^{-1}\right]}\end{array}$ & $\begin{array}{c}20^{\circ} \mathrm{C} \\
1 \mathrm{mg} \cdot \mathrm{mL}^{-1}\end{array}$ \\
\hline 8 & 18 & 13 & $2 * 48$ & 9200 & $1.1 .10^{-4}$ & 1 & $2.7 .10^{-4}$ & Micelles \\
1 & 13 & 7 & $2 * 6$ & 1600 & $6.3 .10^{-3}$ & 10 & $6.7 .10^{-3}$ & Unimer \\
3 & 12 & 11 & $2 * 8$ & 2200 & $5.3 \cdot 10^{-4}$ & 1.2 & $5.3 .10^{-4}$ & Unimer \\
\hline
\end{tabular}

${ }^{\mathrm{a}}$ In deionized water (DLS)

${ }^{\mathrm{b}}$ In deionized water (Fluorescence Spectroscopy)

Table 2. Kinetic constants and percentages of CF released from liposomes, determined from the release experiments of Figure 4.

\begin{tabular}{cccccc}
\hline TBCP & $\boldsymbol{F}_{\boldsymbol{\lambda}=\mathbf{5 2 0}}^{\mathbf{n}}$ & $A$ & $B$ & $\boldsymbol{\tau}$ & $\begin{array}{c}\% \mathrm{CF} \\
\text { release } \\
\text { at } 50 \\
\text { min }\end{array}$ \\
\hline 8 & 109.92 & 122.28 & 0.0179 & 18.47 & 62.6 \\
1 & 114.82 & 133.37 & 0.5978 & 5.73 & 83.5 \\
3 & 128.56 & 125.43 & 0.2602 & 14.46 & 75.8 \\
\hline
\end{tabular}

Table 3. Kinetic constants versus temperature, determined from the release experiments in presence of TBCP3 (Figure 5).

\begin{tabular}{ccccc}
\hline $\mathrm{T}\left({ }^{\circ} \mathrm{C}\right)$ & $\boldsymbol{F}_{\boldsymbol{\lambda}=\mathbf{5 2 0}}^{\boldsymbol{t = 0}}$ & $A$ & $B$ & $\boldsymbol{\tau}$ \\
& & & $\begin{array}{c}\text { (min) } \\
\left(\mathrm{min}^{-1}\right)\end{array}$ \\
\hline 20 & 154.65 & 150.99 & 0.065 & 47.62 \\
30 & 182.39 & 126.20 & 0.313 & 7.67 \\
35 & 204.17 & 94.116 & 0.365 & 2.14 \\
40 & 205.92 & 102.43 & n.d. & 2.58 \\
\hline
\end{tabular}

Table 4. BLM Data and qPCR results for the triblock copolymers. 


\begin{tabular}{|c|c|c|c|c|c|c|c|}
\hline TBCP & $\begin{array}{c}\mathbf{T} \\
{\left[{ }^{\circ} \mathbf{C}\right]}\end{array}$ & $\begin{array}{c}\mathbf{P}_{0} \\
{[\%]}\end{array}$ & $\begin{array}{c}I_{\text {mean }} \\
{[p A]} \\
-100 \mathrm{mV}\end{array}$ & $\begin{array}{c}\text { Pore } \\
\text { diameter } \\
\text { [nm] }\end{array}$ & $\begin{array}{l}{[\mathrm{ADN}]_{\text {trans }}} \\
{\left[\mathrm{ng}_{\mathrm{N}} \mathrm{LL}^{-1}\right]}\end{array}$ & $\begin{array}{l}{[\mathbf{A D N}]_{c i s}} \\
{\left[\mathrm{ng} . \mu \mathbf{L}^{-1}\right]}\end{array}$ & $\begin{array}{c}\text { Translocation } \\
\text { Efficiency } \\
{[\%]}\end{array}$ \\
\hline 8 & 25 & 56 & -12 & 0.24 & $280 \pm 31$ & $\begin{array}{c}4.5 .10^{-2} \\
\pm 2.7 .10^{-2}\end{array}$ & 0.02 \\
\hline 1 & 25 & 41 & -2.5 & 0.05 & $71 \pm 38$ & $\begin{array}{c}4.21 .10^{-3} \\
\pm 6.96 .10^{-4}\end{array}$ & $5.9 .10^{-3}$ \\
\hline 3 & 25 & 88 & -5.5 & 0.11 & $170 \pm 13$ & $\begin{array}{c}10^{-4} \\
\pm 6.8 \cdot 10^{-5}\end{array}$ & $5.9 .10^{-5}$ \\
\hline 3 & 37 & 73 & -42.3 & 0.85 & $90 \pm 9$ & $3 \pm 0.3$ & 3.3 \\
\hline
\end{tabular}

TBCP concentration in cis: $10 \mu \mathrm{g} \cdot \mathrm{mL}^{-1}$

T: Working temperature during the translocation experiments

$\mathrm{P}_{0}$ : ratio between time of interactions and time of acquisition

$\mathrm{I}_{\text {mean }}$ : mean current obtained during the acquisition

Pore diameter: determined by a calculation with the values concerning $\alpha$-hemolysin

Translocation efficiency: calculated as the ratio between $[\mathrm{DNA}]_{\mathrm{cis}}$ and $[\mathrm{DNA}]_{\text {trans }}$

\section{ASSOCIATED CONTENT}

Supporting Information. The following files are available free of charge : characterization of TBCPs and BLM experiments in presence of DNA and TBCPs are supplied as Supporting Information.

\section{AUTHOR INFORMATION}

\section{Corresponding Author}

*philippe.guegan@sorbonne-universite.fr 


\section{Author Contributions}

The manuscript was written through contributions of all authors. All authors have given approval to the final version of the manuscript, and do not have any conflict of interest.

\section{ACKNOWLEDGMENT}

This work was supported by grants from Association Françaisecontre les Myopathies (Strategic project 2009, \#15628AFM) (AFM, Evry, France) and Vaincre La Mucoviscidose (VLM; Paris, France).

\section{REFERENCES}

(1) P. Saraswat, R.R. Soni, A. Bhandari, B.P. NagoriIndian J.Pharm.Sci.2009, 71, 488.

(2) D. Ibraheem, A. Elaissari,H. FessiInt.J.Pharm.2014, 459, 70.

(3) J. Laurence,M. FranklinTranslating Gene Therapy to the Clinic, Techniques and Approaches, $1^{\text {st }}$ Ed., Elsevier Inc., London, 2015.

(4) I.M. Verma, N. Somia. Nature1997, 389, 239.

(5) J.S. Sandhu,A. Keating,N. Hozumi,Crit.Rev.Biotechnol.1997, 17, 307.

(6) B.A. Bunnell,R.A. Morgan Clin.Microbiol.Rev.1998, 11, 42.

(7) N. Cartier,S. Hacein-Bey-Abina,C.C. Bartholomae,G. Veres,M. Schmidt,I. Kutschera,M. Vidaud,U. Abel,L. Dal-Cortivo,L. Caccavelli,N. Mahlaoui,V. Kiermer,D. Mittelstaedt,C. Bellesme, N. Lahlou,F. Lefrère,S. Blanche,M. Audit,E. Payen,P. Leboulch,B. L'Homme,P. Bougnères,C. Von Kalle,A. Fischer,M. Cavazzana-Calvo,P. AubourgScience2009, 326, 818.

(8) M. Cavazzana-Calvo,S. Hacein-Bey,G. de Saint Basile,F. Gross,E. Yvon,P. Nusbaum,F. Selz,C. Hue,S. Certain,J.L. Casanova,P. Bousso,F.L. Deist,A FischerScience2000, 288, 669.

(9) S. Rangarajan,L. Walsh,W. Lester,D. Perry,B. Madan,M. Laffan,H. Yu,C. Vettermann,G.F. Pierce,W.Y. Wong,K.J. PasiN.Engl.J.Med.2017, 377, 2519.

(10) E.W.F.W. Alton,D.K. Armstrong,D. Ashby,K.J. Bayfield,D. Bilton,E.V. Bloomfield,A.C. Boyd,J. Brand,R. Buchan,R. Calcedo,P. Carvelli,M. Chan,S.H. Cheng,D.D.S. Collie,S. 
Cunningham,H.E. Davidson,G. Davies,J.C. Davies,L.A. Davies,M.H. Dewar,A. Doherty,J. Donovan,N.S. Dwyer,H.I. Elgmati,R.F. Featherstone,J. Gavino,S. Gea-Sorli,D.M. Geddes,J.S.R. Gibson,D.R. Gill,A.P. Greening,U. Griesenbach,D.M. Hansell,K. Harman,T.E. Higgins,S.L. Hodges,S.C. Hyde,L. Hyndman,J.A. Innes,J. Jacob,N. Jones,B.F. Keogh,M.P. Limberis,P. Lloyd-Evans,A.W. Maclean,M.C. Manvell,McCormick, D.; McGovern, M.; McLachlan, G.; Meng, C.; Montero, M.A.; Milligan, H.; L.J. Moyce,G.D. Murray,A.G. Nicholson,T. Osadolor,J. Parra-Leiton,D.J. Porteous,I.A. Pringle,E.K. Punch,K.M. Pytel,A.L. Quittner,G. Rivellini,C.J. Saunders,R.K. Scheule,S. Sheard,N.J. Simmonds,K. Smith,S.N. Smith,N. Soussi,S. Soussi,E.J. Spearing,B.J. Stevenson,S.G. Sumner-Jones,M. Turkkila,R.P. Ureta,M.D. Waller,M.Y. Wasowicz,J.M. Wilson,P. Wolstenholme-HoggLancet Respir.Med.2015, 3, 684.

(11) V.A. Sansone,E. Albamonte,F. Salmin,J. Casiraghi,A. Pirola,M. Bettinelli,F. Rao,L. Mancini,N. Tovaglieri,F. Fedeli,P. Stoia,M. Heinen,V. Cozzi,E. Carraro,C. Lunetta,A. Di Bari,E. MercuriNeurol.Sci.2019, 40, 327.

(12) R.S. Finkel,E. Mercuri,B.T. Darras,A.M. Connolly,N.L. Kuntz,J. Kirschner,C.A. Chiriboga,K. Saito,L. Servais,E. Tizzano,H. Topaloglu,M. Tulinius,J. Montes,A.M. Glanzman,K. Bishop,Z.J. Zhong, S. Gheuens,C.F. Bennett,E. Schneider,W. Farwell,N.Engl.J.Med.2017, 377, 1723.

(13) Y. Yue,X. Pan,C.H. Hakim,K. Kodippili,K. Zhang,J.-H. Shin,H.T.; Yang,T. McDonald,D. DuanHum.Mol.Genet.2015, 24, 5880.

(14) L.Xu,K.H.Park, L. Zhao, J.Xu, M. El Refaey, Y. Gao , H. Zhu, J. Ma, R. Han Molecular therapy: the journal of the American Society of Gene Therapy201624, 3 : 564.

(15) C.E. Thomas, A. Ehrhardt,M.A. Kay Nature2003, 4, 346.

(16) M. Ramamoorth,A. Narvekar,J.Clin.Diagn.Res.2015, 9, GE01-GE06.

(17) J.A. St George, Gene Ther. 2003, 10, 1135.

(18) C.H. Evans,S.C. Ghivizzani,P.D. RobbinsArthritis Res.Ther. 2008, 10, 1.

(19) A. Aied,U. Greiser,A. Pandit,W. Wang,Drug Discov. Today2013, 18, 1090.

(20) H. Parhiz,W.T. Shier,M. RamezaniInt.J.Pharm.2013, 457, 237.

(21) G. Yang,F. Lv,B. Wang,L. Liu,Q. Yang,S. WangMacromol.Biosci.2012, 12, 1600.

(22) S. O'Rorke,M. Keeney,A. PanditProgr. Polymer Sci.2010, 35, 441.

(23) C. Roques, Y. Fromes,E. FattalEur.J.Pharm.Biopharm. 2009, 72, 378. 
(24) P.P. Kundu, V. Sharma Curr.Opin.SolidSt.M.2008, 12, 89.

(25) S.Y. Wong,J.M. Pelet,D. Putnam,Progr. Polymer Sci.2007, 32, 799.

(26) D.W. Pack,A.S. Hoffman,S. Pun,P.S. StaytonNat.Rev. Drug Discov. 2005, 4, 581.

(27) R. Gardlík,R. Pálffy,J. Hodosy,J. Lukács,J. Turňa,P. CelecMed.Sci.Monit.2005, 11, RA110.

(28) T.V. Chirila,P.E. Rakocsy,K.L. Garrett,X. Lou,I.J. ConstableBiomaterials2002, 23, 312.

(29) A. Prokop,E. Kozlov,W. Moore,J.M. DavidsonJ.Pharm.Sci.2002, 91, 67.

(30) S. Zhanga,Y. Xua,B. Wanga,W. Qiaob,D. Liub,Z. Li J.Control. Release2004, 100, 165.

(31) M.Dréan, A. Debuigne, C. Goncalves, C. Jérome, P. Midoux, J. Rieger, P. GuéganBiomacromolecules2017, 18 (2), pp 440-451.

(32) M. Neu,D. Fischer,T. KisselJ.Gene Med.2005, 7, 992.

(33) G. BorchardAdv.DrugDeliv.Rev.2001, 52, 145.

(34) V. LoczenskiRose,F. Mastrotto,G. MantovaniPolym.Chem.2017, 8, 353.

(35) C. Roques,E. Fattal,Y. FromesJ.GeneMed.2009, 3, 240.

(36) P. Richard,F. Bossard,L. Desigaux,C. Lanctin,M. Bello-Roufaï,B. PitardHum. Gene Ther.2005, 16, 1318.

(37) R. Chèvre,O. LeBihan,F. Beilvert, B. Chatin, B. Barteau,M. Mével,O. Lambert,B. PitardNucleic Acids Res.2011, 39, 1610.

(38) P. Lemieux, N. Guérin,G. Paradis,R. Proulx,L. Chistyakova, A. Kabanov, V. AlakhovGene Ther.2000, 7, 986.

(39) Z. Yang,J. Zhu,S. Sriadibhatla,C. Gebhart,V. Alakhov,A. KabanovJ.Control. Release2005, 108, 496.

(40) C.Roques,K.Bouchemal,G. Ponchel,Y. Fromes,E.FattalJ.Control. Release2009, 138, 71.

(41) M. Bello-Roufai, O. Lambert,B. PitardNucleic Acids Res.2007, 35, 728.

(42) D. Alimi-Guez,C. Leborgne,G. Pembouong, L. VanWittenberghe,N. Mignet, D. Scherman,A. KichlerJ.Gene Med.2009, 11, 1114.

(43) K. Knop,R. Hoogenboom,D. Fischer,U.S. SchubertAngew.Chem.Int.Ed.2010, 49, 6288.

(44) B. Brissault,A. Kichler,C. Leborgne,N. Jarroux,H. Cheradame, C. GuisChem. Med. Chem.2007, 2, 1202.

(45) C. Pomel, C. Leborgne,H. Cheradame,D. Scherman,A. Kichler,P. GuéganPharm.Res.2008, 25, 2963. 
(46) H. Cheradame,B. Brissault,C. Guis,P. Guégan,C. Pomel,A. Kichler,J. Gau-Racine,L. AuvrayMacromol.Symp.2006, 240, 166.

(47) H. Cheradame,M. Sassatelli,C. Pomel,A. Sanh,J. Gau-Racine,L. Bacri,L. Auvray,P. GuéganMacromol.Symp.2008, 261, 167.

(48) S. Guiraud,D. Alimi-Guez,L. VanWittenberghe,D. Scherman,A. KichlerMacromol.Biosci.2011, 11, 590.

(49) C.-W. Chang,D. Choi,W.J. Kim,J.W. Yockman,L.V. Christensen,Y.-H. Kim, S.W. KimJ.Control.Release2007,118, 245.

(50) B.Pitard,M.Bello-

Roufai,O.Lambert,P.Richard,L.Desigaux,S.Fernandes,C.Lanctin,H.Pollard,M. Zeghal,P.Y. Rescan, D. Escande2004, 32, e159.

(51) S. Sriadibhatla,Z. Yang,C. Gebhart, V.Y. Alakhov,A. KabanovMol.Ther.2006, 13, 804.

(52) M.D. Lavigne,M. Pohlschmidt,J.F. Novo,B. Higgins,V. Alakhov,H. Lochmuller,H. Sakuraba,G. Goldspink,K. MacDermot,D.C. GoreckiMol.Ther.2005, 12, 985.

(53) G. Sahay,E.V. Batrakova,A.V. KabanovBioconjug.Chem.2008, 19, 2023.

(54) T. Demina,I. Grozdova,O. Krylova,A. Zhirnov,V. Istratov,H. Frey,H. Kautz,N. MelikNubarovBiochem.2005, 44, 4042.

(55) J. Gau-Racine,J. Lal,M. Zeghal,L. AuvrayJ.Phys.Chem. B2007, 111, 9900.

(56) G. Pembouong,N. Morellet,T. Kral,M. Hof,D. Scherman,M.-F. Bureau,N. MignetJ.Control.Release2011,151, 57.

(57) C. Huin,T. Le Gall,B. Barteau,B. Pitard,T. Montier,P. Lehn,H. Cheradame,P. GuéganJ.Gene Med.2011, 13, 538.

(58) W.H. BinderAngew.Chem.Int.Ed.2008, 47, 3092.

(59) E. Amado,J. KresslerCurr.Opin. Colloid Interface Sci.2011, 16, 491.

(60) J. Chen,J. Luo,Y. Zhao,L. Pu,X. Lu,R. Gao,G. Wang,Z. GuACS Appl.Mater. Interfaces2015, 7, 7282.

(61) B. Rasolonjatovo,J.-P. Gomez,W. Même,C. Gonçalves,C. Huin,V. Bennevault-Celton, T. Le Gall,T. Montier,P. Lehn,H. Cheradame,P. Midoux,P. GuéganBiomacromolecules2015, 16,748 .

(62) Z.Eskandani,T.Le Gall,T.Montier,P. Lehn,F.Montel,L.Auvray,

C.Huin,P.GuéganEur.Phys.J. E2018, 41, 132. 
(63) Y. Wang,E.J. GoethalsMacromolecules2000, 33, 808.

(64) P.V. Caeter,E.J. Goethals, V. Gancheva,R. VelichkovaPolym.Bull.1997, 39, 589.

(65) M.F. Dubreuil,N.G. Farcy,E.J. GoethalsMacromol.RapidCommun.1999, 20, 383.

(66) R.C. MacDonald,R.I. MacDonald,B.P.M. Menco,K. Takeshita,N.K. Subbarao,L.-R. HuBiochim.Biophys. ActaBiomembr.1991, 1061, 297.

(67) H. Bullova,P. Balgavy,ActaFac.Pharm.Univ.Comen.2005, 52, 66.

(68) J.N. Weinstein,S. Yoshikami,P. Henkart,R. Blumenthal,W.A. HaginsScience1977,195, 489.

(69) J.P. Mata,P.R. Majhi,C. Guo,H.Z. Liu,P. BahadurJ. Colloid Interface Sci.2005, 292, 548.

(70) A. V. Kabanova , E.V. Batrakovaa, V.Y. AlakhovJournal of Controlled Release200282 189.

(71) P. Balgavy, M. Dubnickova, D. Uhrikova, S. Yaradaikin, M. Kiselev, V. Gordeliy, Acta Phys. Slovaca1998, 48, 509.

(72) H. Hauser,D. Oldani,M.C. Phillips Biochem.1973, 12, 4507.

(73) R. Ferdani,R. Li,R. Pajewski,J. Pajewska,R.K. Winter,G.W. GokelOrg.Biomol.Chem.2007, 5, 2423.

(74) J.R. Lakowicz, Principles of fluorescence spectroscopy, Springer Science, New York, 2006, 953.

(75) R. Pajewski,R. Ferdani,J. Pajewska,N. Djedovic,P.H. Schlesinger,G.W. GokelOrg.Biomol.Chem.2005, 3, 619.

(76) S.;Rex, G. SchwarzBiochem.1998, 37, 2336.

(77) M. Saito, S.J. Korsmeyer,P.H. SchlesingerNat.Cell.Biol.2000, 2, 553.

(78) L. Song,M.R. Hobaugh,C. Shustak,S. Cheley,H. Bayley,J.E. GouauxScience1996, 13, 1859.

(79) B. Hille,Ion channels of excitable membranes. $3^{\text {rd }}$ ed., Sinauer Associates, Sunderland, MA, 2001.

(80) P. Richard-Fiardo, E. Payen, R. Chèvre, J. Zuber, E. Letrou-Bonneval, Y. Beuzard, B. PitardHum Gene Ther2008, 19: 331.

(81) P. Richard, F. Bossar, L. Desigaux,C. Lanctin,M. Bello-Roufai,B. PitardHum Gene Ther200516: 1318. 
(82) P. Richard, H. Pollard, C. Lanctin, M. Bello-Roufaï, L. Désignaux, D. Escande, B. Pitard J Gene Med20057: 80.

(83) B. Pitard, H. Pollard, O. Agbulut, O. Lambert, J.T. Vilquin, Y. Cherel, J. Abadie, J. L. Samuel, J.L. Rigaud, S. Menoret, I. Anegon, D. EscandeHum Gene Ther200213: 1767.

(84) J. Cany, B. Barteau, L. Tran, V. Gauttier, I. Archambeaud, J.P. Couty, B. Turlin, B. Pitard, G. Vassaux, N. Ferry, S. ConchonJ Hepatol201154: 115.

(85) C. Rolland-Debord, D. Lair, T. Rousset-Bihouée, D. Hassoun, J. Evrard, M. A. Cheminant, J. Chesné, F. Braza, G. Mahay, V. Portero, C. Sagan, B. Pitard, A. MagnanPLoS One20149: e85976.

(86) B. Cambien, P. Richard-Fiardo, B.F. Karimdjee, V. Martini, B. Ferrua, B. Pitard, H. Schmid-Antomarchi, A. Schmid-AllianaPLoS One20116: e28842.

(87) M.A. Firestone,A.C. Wolf,S. Seifert Biomacromolecules2003, 4, 1539.

TOC Figure.

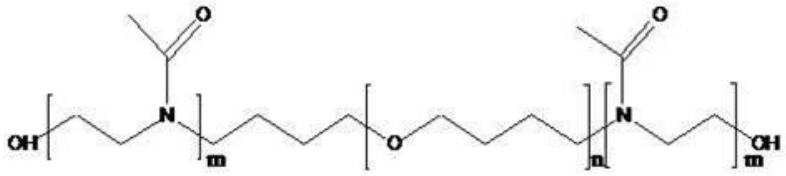

ABA triblock copolymer TBCP

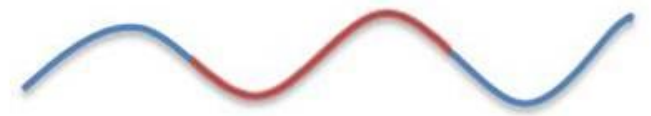

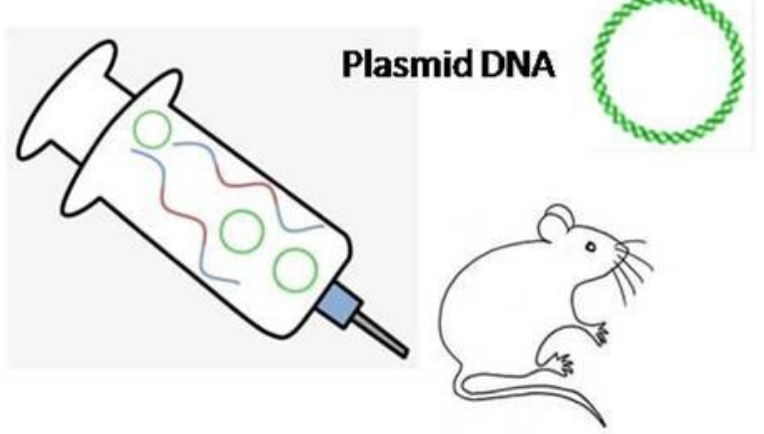

TOC Texte :

Amphiphilic neutral block copolymers having a LCST close to $37^{\circ} \mathrm{C}$ are shown to improve gene transfer via in vivo intramuscular administration at low concentration.Physico-chemical 
experiments demonstrate that permeation of lipid membrane by this block copolymers is the factor that improves the gene delivery, when temperature is increased from $20^{\circ} \mathrm{C}$ to $37^{\circ} \mathrm{C}$.

KEYWORDS. Amphiphilic copolymers; in vivo transfection; LCST; poly(2-methyl-2oxazoline); skeletal muscle. 